\title{
Different outcome in node-positive breast cancer patients found by axillary ultrasound or sentinel node procedure
}

\author{
Nicole C. Verheuvel ${ }^{1}$ Adri C. Voogd ${ }^{2,3,4}$ • Vivianne C. G. Tjan-Heijnen ${ }^{4}$. \\ S. Siesling ${ }^{3,5} \cdot$ Rudi M. H. Roumen ${ }^{1,4}$
}

Received: 9 March 2017 / Accepted: 13 June 2017 / Published online: 27 June 2017

(c) The Author(s) 2017. This article is an open access publication

\begin{abstract}
Background The Z0011 trial initiated a paradigm shift in the axillary treatment of breast cancer patients with a positive sentinel lymph node biopsy (SLNB), disregarding patients with a positive ultrasound-guided lymph node biopsy (UGLNB). We examined whether relevant differences exist between these patients to determine if the conclusions of the ACOSOG Z0011 trial are applicable to UGLNB-positive patients.

Methods Patients diagnosed with invasive breast cancer in the Netherlands between January 2008 and December 2014 were selected from the Netherlands Cancer Registry. Results A total of 11,820 cases were included: 9149 cases in the SLNB group and 2671 in the UGLNB group. Multivariate analyses showed that UGLNB-positive patients were older $(p<0.001)$, more likely to have a poorly
\end{abstract}

The contents of this article have been presented in a poster presentation at the San Antonio Breast Cancer Symposium 2016.

Nicole C. Verheuvel

n.verheuvel@mmc.nl

1 Department of Surgery, Máxima Medical Center, PO Box 7777, 5500 MB Veldhoven, The Netherlands

2 Department of Epidemiology, School of Oncology and Developmental Biology (GROW), Maastricht University Medical Centre, Maastricht, The Netherlands

3 Department of Research, Netherlands Comprehensive Cancer Organisation (IKNL), Utrecht, The Netherlands

4 Department of Medical Oncology, School of Oncology and Developmental Biology (GROW), Maastricht University Medical Centre, Maastricht, The Netherlands

5 Department of Health Technology and Services Research, MIRA Institute for Biomedical Technology and Technical Medicine, University of Twente, Enschede, The Netherlands differentiated tumor $(p<0.001)$, had a negative hormone receptor status $(p<0.001)$, and more often had extensive nodal involvement $(p<0.001)$. However, they were less likely to undergo adjuvant radiation $(p=0.004)$ or systemic therapy $(p<0.001)$. Even after adjusting for these factors, UGLNB-positive patients had a worse overall survival $(\mathrm{HR}=1.38 ; 95 \%$ CI $1.23-1.56)$ than SLNBpositive patients.

Conclusion This nationwide retrospective study shows that young patients found positive by UGLNB have less favorable disease characteristics and a worse prognosis compared to patients with a positive SLNB. Selection by ultrasound plays an important role when axillary treatment strategies are considered. Hence, the conclusions of the Z0011 trial cannot unconditionally be applied to patients with a positive UGLNB.

Keywords Ultrasound Sentinel node - Breast cancer . Survival

\section{Introduction}

Determining the axillary lymph node status is still an important element in the diagnostic work-up of patients with invasive breast cancer. This is mostly done by ultrasound-guided lymph node biopsy (UGLNB) or sentinel lymph node biopsy (SLNB) [1]. Until recently, a positive lymph node was immediately followed by an axillary lymph node dissection (ALND) to obtain locoregional disease control and to determine the need for adjuvant systemic treatment [1-4]. However, multiple studies have shown that in 40-70\% of the patients with a positive SLNB the remaining non-SLNs do not contain any metastases [5-7]. As a consequence, the indication for adjuvant 
treatment has become increasingly dependent on other prognostic factors, such as age, tumor size, tumor grade, hormone and HER2 receptor status, and gene expression profiles [1, 8-10]. These developments raised questions on the necessity of performing an ALND in patients with a positive SLNB [6, 11].

Results from the American College of Surgeons Oncology Group (ACOSOG) Z0011 trial initiated a paradigm shift in the management of invasive breast cancer. This study showed that an ALND can be safely omitted in patients with a positive SLNB, treated with breast-conserving surgery (including radiotherapy) and adjuvant systemic therapy, even after a follow-up of nearly 10 years $[12,13]$. However, UGLNB-positive patients were excluded in this study. In order to assess whether the conclusions of the Z0011 trial can also be applied to these patients, we have previously conducted a study among 302 node-positive patients to examine whether UGLNB-positive patients were comparable to SLNB selected positive patients with respect to important clinicopathological factors and prognosis. That study showed that UGLNB-positive patients had worse tumor characteristics and consequently had a worse disease-free and overall survival compared to patients with a positive SLNB [14].

However, these results were based on a small patient population treated in only one non-academic teaching hospital. We therefore perform this study in a nationwide population-based dataset containing data of breast cancer patients without palpable lymphadenopathy to examine whether relevant differences in disease characteristics and prognosis exist between patients selected by UGLNB versus SLNB to determine if the conclusions of the ACOSOG Z0011 trial are applicable to UGLNB-positive patients.

\section{Patients and methods}

This population-based study included patients diagnosed with clinical stage $T_{1}$ or $T_{2}$ node-positive invasive breast cancer between 2008 and 2014 in the Netherlands. Data were retrieved from the population-based Netherlands Cancer Registry (NCR), which is a prospectively maintained database of all malignancies diagnosed in the Netherlands, based on notification by the Dutch nationwide pathology archive (PALGA) since 1989, containing information directly from patients' medical records in all hospitals in the Netherlands. The use of these data was approved by the NCR Committee of Privacy.

Historically, all breast cancer patients underwent an ALND for axillary staging. The SLNB was officially incorporated in the Dutch guideline in 2004 [15]. Ever since the guidelines of 2008, it was recommended to perform sonographic evaluation of the axilla in all breast cancer patients with ultrasound-guided biopsies of the tumor and of suspicious axillary lymph nodes, irrespective of the palpability of the lymph node, prior to the SLNB $[1,16]$. Histological biopsies of the breast tumor were performed using a 14-gauge or 18-gauge needle, whereas suspicious lymph nodes were biopsied for cytological analysis using a 21-gauge hollow needle. If pathological analysis showed that the ultrasound-guided biopsy was negative or inconclusive, patients underwent a SLNB. For the current analysis, only patients without clinically palpable lymphadenopathy $\left(\mathrm{cN}_{0}\right)$ who had node-positive disease after an ALND were included. Patients with stage IV breast cancer, with clinical stage $T_{3}-T_{4}$ breast tumor according to the TNM classification [1], those receiving neoadjuvant systemic treatment, those with palpable axillary nodes $(\mathrm{cN} \geq 1)$, and those who did not undergo an ALND were excluded.

\section{Data analyses}

Clinical data included in the analysis were as follows: age, year of diagnosis, lateralization of the tumor, and type of surgery (mastectomy or breast conserving), and clinical TNM classification. Histopathological data collected on the tumor included tumor size according to the TNM classification [1], tumor morphology, tumor grade according to the Nottingham grading scale, and hormone and HER2 receptor status. Estrogen and progesterone receptor status were considered positive if $10 \%$ or more of the material contained the appropriate receptors. The presence of a multifocal tumor was also included in the analysis and was defined as tumors occurring in multiple sites in the breast. Information on whether or not patients had received an axillary ultrasound was not available in the NCR. Therefore, the group "UGLNB-positive patients" consisted of those patients who had a positive nodal status after an ALND, but did not undergo a previous SLNB. The total number of resected lymph nodes and the total number of positive lymph nodes included all nodes, either found after SLNB or after ALND. The total number of positive axillary lymph nodes was used to define the extent of nodal involvement, which was categorized as minimal nodal involvement (one or two positive nodes) or extensive nodal involvement (three or more positive lymph nodes), as proposed by the Z0011 trial.

In univariate analyses, the Chi-square test was used to compare differences in patient and tumor characteristics between patients who possibly had a positive UGLNB (UGLNB group) versus those with a positive SLNB (SLNB group). Survival analyses were conducted using the Kaplan-Meier method and a multivariate Cox regression analysis to calculate the Hazard Ratio (HR). A $p$ value of 
$\leq 0.1$ in univariate analysis was considered statistically significant and used as a threshold for inclusion of a covariate in the multivariate Cox regression analysis to establish whether the significant association between method of axillary staging and overall survival was influenced by these covariates. Overall survival was calculated from the date of diagnosis until death or last documentation. Follow-up was updated until December 2015. A $p$ value of $\leq 0.05$ in multivariate analysis was considered statistically significant.

\section{Results}

From January 2008 until December 2014, a total of 95,454 patients were diagnosed with invasive breast cancer in the Netherlands. Their median age was 59 years, ranging from 21 to 97 years. After applying inclusion and exclusion criteria, as summarized in Fig. 1, a total of 11,820 patients had one or more positive lymph nodes and underwent an ALND. Of these patients, 9149 had a positive SLNB and the remaining 2671 were included in the UGLNB group.

\section{Differences in characteristics}

Table 1 shows the distribution and the results of univariate analyses on patient and tumor characteristics between UGLNB-positive patients versus those with a positive SLNB. These results show a shift from node-positive diagnoses by ultrasound in the earlier years to a positive SLNB later on. Furthermore, analyses on patient and tumor characteristics showed that node-positive patients diagnosed by SLNB significantly differed from patients in the UGLNB group; the UGLNB group was older, was more often diagnosed in the period 2008-2011, had a larger tumor, had a poorly differentiated tumor, was more likely to have a negative hormone receptor status, had a multifocal tumor, had undergone a mastectomy, and was less likely to receive adjuvant radiation therapy or systemic therapy.

\section{Overall survival}

The median follow-up time was 5 years, ranging up to 8 years. During follow-up, a total of 1542 patients (12.2\%) died. The 5-year survival was $81.6 \%$ for the UGLNB group and $89.6 \%$ for the SLNB group $(p<0.001)$. Univariate Cox regression of the overall survival resulted in a hazard ratio (HR) of 1.82 (95\% CI 1.64-2.02) for patients with a positive UGLNB compared to patients with a positive SLNB (Fig. 2).

Multivariate backward Cox regression analysis, adjusting for age at diagnosis, year of diagnosis, type of surgery, hormone receptor status, tumor morphology, tumor size, tumor grade, multifocality, number of positive lymph nodes, radiation therapy, and adjuvant systemic therapy, showed that a positive UGLNB remained significantly associated with a worse overall survival compared to a positive SLNB (HR $=1.38 ; 95 \%$ CI $1.23-1.56 ; p<0.001)$ (Table 2).

In addition, we performed a sensitivity analysis excluding patients aged 70 years or older. These analyses showed that, during crude analyses, having a positive UGLNB was still significantly associated with a worse overall survival $(\mathrm{HR}=1.21,95 \%$ CI $1.03-1.43)$. However, multivariate cox regression analyses, adjusting for the aforementioned variables, show that method of axillary staging is no longer statistically significant $(\mathrm{HR}=1.13$, 95\% CI 0.94-1.35).

\section{Discussion}

The present nationwide, population-based study aimed to examine whether node-positive breast cancer patients found by UGLNB differ from those with a positive SLNB. It should be noticed that only patients without clinically palpable lymph nodes $\left(\mathrm{cN}_{0}\right)$ and with small tumors $\left(p T_{1}-\right.$ $T_{2}$ ) were studied. It appears that pathologically node-positive patients selected by ultrasound had significantly worse disease characteristics and a worse overall survival compared to patients selected by SLNB, even after correction for possible confounders. However, this association was no longer existent when excluding patients aged 70 years or older. Thus, selection by axillary ultrasound appears to be an independent prognostic factor in patients younger than 70 years.

In a previous small single-center study, we examined this question in all breast cancer patients with and without clinically palpable lymphadenopathy. It was shown that patients with a positive UGLNB had worse disease characteristics and a higher axillary tumor burden [14]. This resulted in a worse disease-free $(\mathrm{HR}=2.71 ; 95 \% \mathrm{CI}$ 1.49-4.92) and overall survival $(\mathrm{HR}=2.67 ; 95 \% \mathrm{CI}$ 1.48-4.84) compared to patients with a positive SLNB. However, due to the small study population it was not possible to perform multivariate analyses to correct for confounding factors, as was done in the current study. The above-formulated question is of course most relevant for patients with a clinically negative axillary nodal status [17-22]. The current study has shown that having a positive UGLNB is associated with a worse survival in patients younger than 70 years, even after adjustment for known predictors of a worse prognosis, such as tumor size, tumor grade, hormone status, and number of positive lymph nodes $[6,11,23-25]$. Thus, being node positive after an UGLNB 
Fig. 1 Flowchart of patient selection, using TNM classification [1], showing the inclusion of 2671 cases in the UGLNB group and 9149 cases in the SLNB group with positive lymph nodes after ALND. $A L N D$ axillary lymph node dissection, SLNB group patients with a positive sentinel lymph node biopsy, UGLNB group patients with a positive ultrasound-guided lymph node biopsy

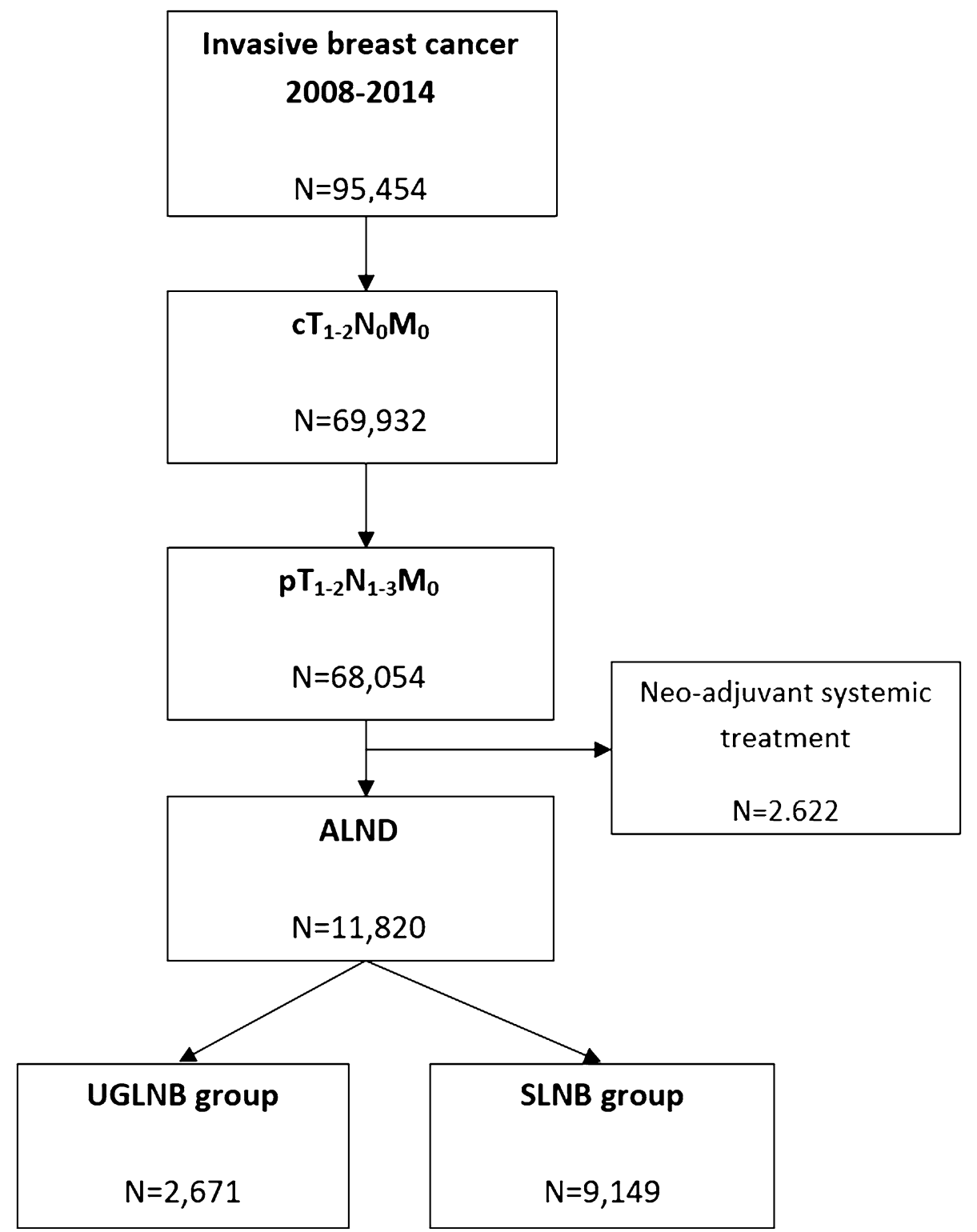

is a very important prognostic indicator in young breast cancer patients.

Furthermore, the present data demonstrate the ongoing shift in diagnostic work-up of the axillary lymph nodes over time. This has previously been described by Beek et al. [26] demonstrating the radical transformation in the work-up and management of the axilla in the southern Netherlands. Ever since 2004, Dutch guidelines recommend to perform a SLNB prior to an ALND for axillary staging. Although the axillary ultrasound was not yet a standard element of the diagnostic work-up, the guideline considered it to be useful for patient selection prior to the SLNB. In the guideline of 2008, the UGLNB was officially introduced as an additional diagnostic method preceding the SLNB $[15,16]$. Therefore, since sonographic data were missing, patients who did not have a SLNB were included in the UGLNB group. The UGLNB group could therefore contain patients who underwent an immediate ALND, although this number should be limited.

Since the Z0011 trial has caused a paradigm shift in the management of invasive breast cancer, one might wonder whether the selection process of the axillary status may affect the applicability of its conclusions. The Z0011 demonstrated that in patients with $T_{1-2}$ invasive breast cancer treated with breast-conserving therapy, including radiotherapy, and two or less positive sentinel nodes, the ALND could be omitted without affecting the prognosis [12]. However, some doubts were raised regarding the applicability of these Z0011 criteria in general practice, since this trial only included a selected group of nodepositive patients detected by the SLNB [27, 28]. Multiple studies have shown a large variability in the proportion of 
Table 1 Univariate analysis of patient and tumor characteristics in patients staged $p T_{1}-T_{2}$ with positive axillary lymph nodes identified by ultrasound versus sentinel node biopsy

\begin{tabular}{|c|c|c|c|}
\hline Patient characteristics & UGLNB $(n=2671)$ & $\operatorname{SLNB}(n=9149)$ & $p$ value \\
\hline Gender & & & 0.741 \\
\hline Male & $21(0.8 \%)$ & $78(0.9 \%)$ & \\
\hline Female & $2650(99.2 \%)$ & $9071(99.1 \%)$ & \\
\hline Age & & & $<0.001$ \\
\hline Median [range] & 63 [23-97] & 58 [21-95] & \\
\hline$<50$ years & $590(22.1 \%)$ & $2305(25.2 \%)$ & \\
\hline 50-69 years & $1155(43.2 \%)$ & $5045(55.1 \%)$ & \\
\hline$\geq 70$ years & $926(34.7 \%)$ & $1799(19.7 \%)$ & \\
\hline Year of diagnosis & & & $<0.001$ \\
\hline 2008-2011 & $2246(84.1 \%)$ & $6788(74.2 \%)$ & \\
\hline 2012-2014 & $425(15.9 \%)$ & $2361(25.8 \%)$ & \\
\hline Side of tumor & & & 0.932 \\
\hline Right & $1310(49.0 \%)$ & $4494(49.1 \%)$ & \\
\hline Left & $1361(51.1 \%)$ & $4655(50.9 \%)$ & \\
\hline Type of surgery & & & $<0.001$ \\
\hline Breast conserving & $649(24.3 \%)$ & $4464(48.8 \%)$ & \\
\hline Mastectomy & $2022(75.7 \%)$ & $4685(51.2 \%)$ & \\
\hline Tumor stadium (TNM) & & & $<0.001$ \\
\hline pT1a & $51(1.9 \%)$ & $88(1.0 \%)$ & \\
\hline pT1b & $247(9.2 \%)$ & $801(8.8 \%)$ & \\
\hline pT1c & $1082(40.5 \%)$ & $4222(46.1 \%)$ & \\
\hline pT2 & $1291(48.3 \%)$ & $4038(44.1 \%)$ & \\
\hline Morphology of tumor & & & $<0.001$ \\
\hline Ductal carcinoma & $1970(73.8 \%)$ & $7116(77.8 \%)$ & \\
\hline Lobular carcinoma & $351(13.1 \%)$ & $1097(12.0 \%)$ & \\
\hline Other types & $350(13.1 \%)$ & $936(10.2 \%)$ & \\
\hline Tumor grade & & & $<0.001$ \\
\hline Grade 1 & $497(18.6 \%)$ & $1948(21.3 \%)$ & \\
\hline Grade 2 & $1235(46.2 \%)$ & $4414(48.2 \%)$ & \\
\hline Grade 3 & $838(31.4 \%)$ & $2518(27.5 \%)$ & \\
\hline Unknown & 101 & 269 & \\
\hline ER status & & & $<0.001$ \\
\hline Negative & $302(11.3 \%)$ & $579(6.3 \%)$ & \\
\hline Positive & $2254(84.4 \%)$ & $8080(88.3 \%)$ & \\
\hline Unknown & 115 & 490 & \\
\hline PR status & & & $<0.004$ \\
\hline Negative & $578(21.6 \%)$ & $1327(14.5 \%)$ & \\
\hline Positive & $1825(68.3 \%)$ & $6571(71.8 \%)$ & \\
\hline Unknown & 787 & 1251 & \\
\hline HER2 status & & & 0.474 \\
\hline Negative & $2271(85.0 \%)$ & $7912(86.5 \%)$ & \\
\hline Positive & $328(12.3 \%)$ & $1089(11.9 \%)$ & \\
\hline Unknown & 72 & 148 & \\
\hline Multifocality & & & $<0.001$ \\
\hline No & $1726(64.6 \%)$ & $7291(79.7 \%)$ & \\
\hline Yes & $928(34.7 \%)$ & $1808(19.8 \%)$ & \\
\hline Unknown & 17 & 50 & \\
\hline
\end{tabular}


Table 1 continued

\begin{tabular}{llll}
\hline Patient characteristics & UGLNB $(n=2671)$ & SLNB $(n=9149)$ & $p$ value \\
\hline $\begin{array}{l}\text { Total positive lymph nodes } \\
\text { Median [range] }\end{array}$ & $1[1-29]$ & $1[1-34]$ & $<0.001$ \\
$1-2$ nodes & $2243(84.0 \%)$ & $7196(78.6 \%)$ & \\
3 or more nodes & $413(15.4 \%)$ & $1944(21.2 \%)$ & \\
Unknown & 15 & 36 & $<0.001$ \\
Radiotherapy & & & \\
No & $1650(61.8 \%)$ & $3722(40.7 \%)$ & $<0.001$ \\
Yes & $1021(38.2 \%)$ & $5427(59.3 \%)$ & \\
Adjuvant systemic therapy & & $876(9.6 \%)$ & \\
No & $647(24.2 \%)$ & $8273(90.4 \%)$ & \\
Yes & $2024(75.8 \%)$ & $1109(13.4 \%)$ & \\
Chemotherapy & $284(14.0 \%)$ & $2468(29.8 \%)$ & \\
Hormone therapy & $833(41.2 \%)$ & $4696(56.8 \%)$ & \\
Both & $907(44.8 \%)$ & & \\
\hline
\end{tabular}

$U G L N B$ ultrasound-guided lymph node biopsy, SLNB sentinel lymph node biopsy, ER status estrogen receptor status, $P R$ status progesterone receptor status

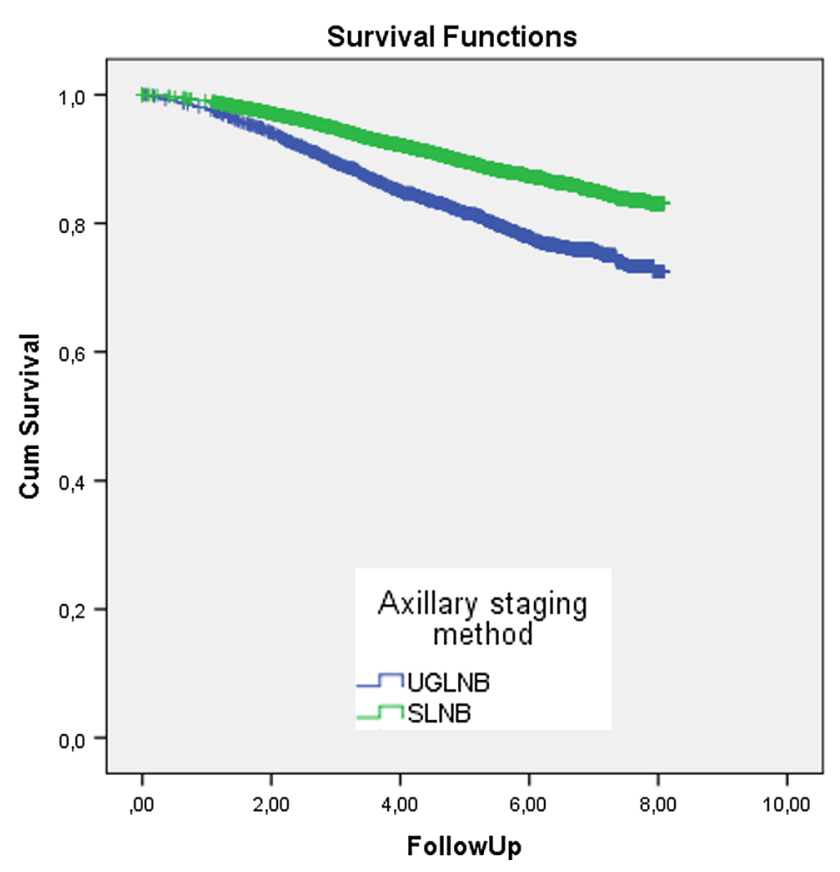

Fig. 2 Kaplan-Meier curve of overall survival in years; SLNB group versus UGLNB group $(p<0.001)$. SLNB group patients with a positive sentinel lymph node biopsy, UGLNB group patients with a positive ultrasound-guided lymph node biopsy

patients who fulfill the inclusion criteria of the Z0011 trial, ranging from 9 to $75 \%$ [29-32]. This wide range is caused by differences in methods of inclusion and differences in the axillary work-up. Nevertheless, a number of health care centers have already implemented the Z0011 criteria into clinical practice, not only on patients who fit the Z0011 criteria, but also on other subgroups [26, 31, 33-37]. Unquestionably, application of the Z0011 criteria results in a substantial reduction of the number of unnecessary ALNDs within a specific group of node-positive patients $[38,39]$. However, in patient categories which were not included in the Z0011 trial, such as patients who need a mastectomy or those with a positive UGLNB, ALND or axillary radiotherapy might still be necessary and recommended $[27,38]$. These patients therefore remain at risk for the morbidity associated with these axillary treatment strategies.

Various studies have been performed on the clinical utility of UGLNB and on the applicability of the conclusions of the Z0011 trial on UGLNB-positive patients. Farrel et al. [39] examined the role of axillary ultrasound as a preoperative staging method. They performed subgroup analyses on patients who would be eligible for application of the Z0011 criteria if they were primarily staged by the SLNB. It was concluded that patients with a positive UGLNB had a larger axillary nodal burden and were therefore not suitable for application of the Z0011 criteria. On the other hand, patients with a negative UGLNB had minimal axillary nodal burden and were thus probably good candidates for treatment according to the conclusions of the Z0011 trial. In addition, Zgajnar et al. [40] compared node-positive patients who, prior to their SLNB, had either a negative physical examination or a negative UGLNB and concluded that patients with a negative ultrasound had a lower axillary tumor burden than patients who were classified as node negative after physical examination. Therefore, we advise to adhere to the use of UGLNB as a preoperative staging method, since the number of suspicious lymph nodes visualized during axillary ultrasound is predictive for the extent of nodal positivity which may still 
Table 2 Significant results of multivariate backward Cox regression analyses on the association between method of axillary staging and overall survival

\begin{tabular}{|c|c|c|c|}
\hline Characteristics & HR & $95 \% \mathrm{CI}$ & $p$ value \\
\hline \multicolumn{3}{|c|}{ Method of axillary staging } & $<0.001$ \\
\hline SLNB & 1 & & \\
\hline UGLNB & 1.38 & $1.23-1.56$ & \\
\hline \multicolumn{3}{|l|}{ Age at diagnosis } & $<0.001$ \\
\hline$<50$ years & 1 & & \\
\hline $50-69$ years & 1.56 & $1.30-1.88$ & \\
\hline$\geq 70$ years & 4.39 & $4.07-5.88$ & \\
\hline \multicolumn{3}{|l|}{ Tumor grade } & $<0.001$ \\
\hline Grade 1 & 1 & & \\
\hline Grade 2 & 1.21 & $1.03-1.43$ & \\
\hline Grade 3 & 1.82 & $1.52-2.22$ & \\
\hline \multicolumn{3}{|l|}{ ER status } & 0.001 \\
\hline Negative & 1 & & \\
\hline Positive & 0.70 & $0.58-0.86$ & \\
\hline \multicolumn{3}{|l|}{ PR status } & 0.001 \\
\hline Negative & 1 & & \\
\hline Positive & 0.77 & $0.66-0.90$ & \\
\hline \multicolumn{3}{|c|}{ Total positive lymph nodes } & $<0.001$ \\
\hline $1-2$ nodes & 1 & & \\
\hline 3 or more nodes & 1.89 & $1.64-2.19$ & \\
\hline \multicolumn{3}{|l|}{ Radiotherapy } & 0.004 \\
\hline No & 1 & & \\
\hline Yes & 0.77 & $0.64-0.92$ & \\
\hline \multicolumn{3}{|c|}{ Adjuvant systemic therapy } & $<0.001$ \\
\hline No & 1 & & \\
\hline Yes & 0.70 & $0.60-0.82$ & \\
\hline
\end{tabular}

$U G L N B$ ultrasound-guided lymph node biopsy, SLNB Sentinel lymph node biopsy, ER status estrogen receptor status, $P R$ status progesterone receptor status

be relevant for determining the most optimal axillary treatment strategy $[17,18,21,26]$.

The results of the present study endorse that implementing the conclusions of the Z0011 trial should be done with caution, especially since international guidelines differ with regard to the axillary work-up. In the United States, an axillary ultrasound is only performed in patients with clinically palpable lymph nodes, whereas patients without palpable nodes will immediately undergo a SLNB [3]. On the contrary, in Europe basically all breast cancer patients receive an axillary ultrasound and will only undergo a SLNB in case of a negative or inconclusive UGLNB, irrespective of lymph node palpability $[1,2,4]$. Therefore, the patient cohorts underlying the studies, in which axillary nodal status plays a role, differ considerably between the US and Europe, due to the bias introduced by the differences with respect to axillary work-up.
The present retrospective study has some drawbacks. Specific data on the axillary sonographic evaluation were lacking, such as whether the UGLNB was performed at all and the sonographic results (like the number of visible nodes, number and results of the biopsy, etcetera). In order to distinguish patients with a positive UGLNB versus SLNB, we assumed that patients who had an ALND_-but did not undergo a SLNB - had a positive UGLNB. As stated previously, the current UGLNB group may therefore also contain patients in whom an ALND was performed directly without prior axillary staging. However, this number should be limited, since both the UGLNB and the SLNB were a standard element of the axillary work-up, in the years included in this study. Furthermore, the follow-up of this study is limited. This results in missing data on recurrence rate and cause of mortality; therefore, the follow-up period should be extended and should focus on disease-free survival. It is also possible that not all confounders, such as comorbidities and body mass index, were identified due to the retrospective character of this study. Nevertheless, based on the high number of included patients in this study and the fact that these results confirm the findings of a previous study, to our opinion the conclusion of the present analysis should be considered valid and clinically relevant for the selection of node-positive breast cancer patients.

\section{Conclusion}

This multicenter population-based study shows that young clinically node-negative breast cancer patients with pathological node positivity found by UGLNB have less favorable disease characteristics and a worse survival compared to patients selected to be node positive by a SLNB. This diagnostic selection process thus plays an important role when axillary treatment strategies are considered. Therefore, we conclude that the conclusions of the Z0011 trial cannot yet be applied to patients with a positive UGLNB.

Acknowledgements The authors thank the registration teams and scientific staff of the Comprehensive Cancer Centre Netherlands for the collection of data for the Netherlands Cancer Registry.

\section{Compliance with ethical standards}

Conflict of interest None to declare.

Open Access This article is distributed under the terms of the Creative Commons Attribution 4.0 International License (http://crea tivecommons.org/licenses/by/4.0/), which permits unrestricted use, distribution, and reproduction in any medium, provided you give appropriate credit to the original author(s) and the source, provide a 
link to the Creative Commons license, and indicate if changes were made.

\section{References}

1. NABON national guideline breast cancer 2.0; Comprehensive Cancer Centre Netherlands (2012). http://www.oncoline.nl/mam macarcinoom. Accessed Sept 152016

2. Senkus E, Kyriakides S, Ohno S et al (2015) Primary breast cancer: ESMO Clinical Practice Guidelines for diagnosis, treatment and follow-up. Ann Oncol 26(Suppl 5):v8-v30

3. National comprehensive cancer network. NCCN clinical practice guidelines in oncology (NCCN Guidelines); Breast cancer. 1. 2016. http://www.nccn.com. Accessed Sept 152016

4. Mayor S (2009) NICE updates guidance on early and advanced breast cancer. BMJ 338:b815

5. Gur AS, Unal B, Ozbek U et al (2010) Validation of breast cancer nomograms for predicting the non-sentinel lymph node metastases after a positive sentinel lymph node biopsy in a multi-center study. Eur J Surg Oncol 36:30-35

6. Coutant C, Olivier C, Lambaudie E et al (2009) Comparison of models to predict nonsentinel lymph node status in breast cancer patients with metastatic sentinel lymph nodes: a prospective multicenter study. J Clin Oncol 27:2800-2808

7. Nath J, Sami N, Massey J et al (2013) Selection for axillary clearance in breast cancer (ultrasound negative, sentinel node positive patients have low rates of further metastases). Eur J Surg Oncol 39:450-454

8. Arpino G, Generali D, Sapino A et al (2013) Gene expression profiling in breast cancer: a clinical perspective. Breast 22:109-120

9. Drukker CA, Schmidt MK, van Dalen T et al (2014) Gene expression classifiers in the prognosis of breast cancer. Ned Tijdschr Geneeskd 158:A7001

10. Reis-Filho JS, Pusztai L (2011) Gene expression profiling in breast cancer: classification, prognostication, and prediction. Lancet 378:1812-1823

11. Coufal O, Pavlik T, Fabian P et al (2009) Predicting non-sentinel lymph node status after positive sentinel biopsy in breast cancer: what model performs the best in a Czech population? Pathol Oncol Res 15:733-740

12. Giuliano AE, Hunt KK, Ballman KV et al (2011) Axillary dissection vs no axillary dissection in women with invasive breast cancer and sentinel node metastasis: a randomized clinical trial. JAMA 305:569-575

13. Giuliano AE, Ballman K, McCall L et al (2016) Locoregional recurrence after sentinel lymph node dissection with or without axillary dissection in patients with sentinel lymph node metastases: long-term follow-up from the American College of Surgeons Oncology Group (Alliance) ACOSOG Z0011 randomized trial. Ann Surg 264:413-420

14. Verheuvel NC, van den Hoven I, Ooms HW et al (2015) The role of ultrasound-guided lymph node biopsy in axillary staging of invasive breast cancer in the post-ACOSOG Z0011 trial era. Ann Surg Oncol 22:409-415

15. NABON national guideline breast cancer; Comprehensive Cancer Centre Netherlands (2004). http://www.oncoline.nl/mammacarci noom. Accessed Sept 152016

16. NABON national guideline breast cancer; Comprehensive Cancer Centre Netherlands (2008). http://www.oncoline.nl/mammacarci noom. Accessed Sept 152016

17. Abe H, Schacht D, Sennett CA et al (2013) Utility of preoperative ultrasound for predicting pN2 or higher stage axillary lymph node involvement in patients with newly diagnosed breast cancer. AJR Am J Roentgenol 200:696-702

18. Hieken TJ, Trull BC, Boughey JC et al (2013) Preoperative axillary imaging with percutaneous lymph node biopsy is valuable in the contemporary management of patients with breast cancer. Surgery 154:831-838 discussion 838-40

19. Amonkar SJ, Oates E, McLean L et al (2013) Pre-operative staging of the axilla in primary breast cancer. By redefining the abnormal appearing node can we reduce investigations without affecting overall treatment? Breast 22:1114-1118

20. Schipper RJ, van Roozendaal LM, de Vries B et al (2013) Axillary ultrasound for preoperative nodal staging in breast cancer patients: is it of added value? Breast 22:1108-1113

21. Caudle AS, Yi M, Hoffman KE et al (2014) Impact of identification of internal mammary sentinel lymph node metastasis in breast cancer patients. Ann Surg Oncol 21:60-65

22. Verheuvel NC, Ooms HW, Tjan-Heijnen VC et al (2016) Predictors for extensive nodal involvement in breast cancer patients with axillary lymph node metastases. Breast 27:175-181

23. van Wely BJ, de Wilt JH, Schout PJ et al (2013) Ultrasoundguided fine-needle aspiration of suspicious nodes in breast cancer patients; selecting patients with extensive nodal involvement. Breast Cancer Res Treat 140:113-118

24. Katz A, Smith BL, Golshan M et al (2008) Nomogram for the prediction of having four or more involved nodes for sentinel lymph node-positive breast cancer. J Clin Oncol 26:2093-2098

25. van la Parra RF, Ernst MF, Bevilacqua JL et al (2009) Validation of a nomogram to predict the risk of nonsentinel lymph node metastases in breast cancer patients with a positive sentinel node biopsy: validation of the MSKCC breast nomogram. Ann Surg Oncol 16:1128-1135

26. Beek MA, Verheuvel NC, Luiten EJT et al (2015) Two decades of axillary management in breast cancer. $\mathrm{Br} \mathrm{J}$ Surg 102:1658-1664

27. Gatzemeier W, Bruce Mann G (2013) Which sentinel lymphnode (SLN) positive breast cancer patient needs an axillary lymph-node dissection (ALND)-ACOSOG Z0011 results and beyond. Breast 22:211-216

28. Olsen S, Amr B, Omar A et al (2011) Are the findings of applicable to district general hospital unit-and how should they change our practice. Cancer Res 71:355s-356s

29. Guth U, Myrick ME, Viehl CT et al (2012) The post ACOSOG Z0011 era: does our new understanding of breast cancer really change clinical practice? Eur J Surg Oncol 38:645-650

30. Yi M, Kuerer HM, Mittendorf EA et al (2013) Impact of the american college of surgeons oncology group Z0011 criteria applied to a contemporary patient population. J Am Coll Surg 216:105-113

31. Delpech Y, Bricou A, Lousquy R et al (2013) The exportability of the ACOSOG Z0011 criteria for omitting axillary lymph node dissection after positive sentinel lymph node biopsy findings: a multicenter study. Ann Surg Oncol 20:2556-2561

32. Ngui NK, Elder EE, Jayasinghe UW et al (2013) Relevance of the American College of Surgeons Oncology Group Z0011 Trial to breast cancer in the Australian setting. ANZ J Surg 83:924-928

33. Caudle AS, Hunt KK, Tucker SL et al (2012) American College of Surgeons Oncology Group (ACOSOG) Z0011: impact on surgeon practice patterns. Ann Surg Oncol 19:3144-3151

34. Gainer SM, Hunt KK, Beitsch P et al (2012) Changing behavior in clinical practice in response to the ACOSOG Z0011 trial: a survey of the American Society of Breast Surgeons. Ann Surg Oncol 19:3152-3158

35. Joyce DP, Lowery AJ, McGrath-Soo LB et al (2015) Management of the axilla: has Z0011 had an impact? Ir J Med Sci 185:145-149 
36. Caretta-Weyer H, Greenberg CG, Wilke LG et al (2013) Impact of the American College of Surgeons Oncology Group (ACOSOG) Z0011 trial on clinical management of the axilla in older breast cancer patients: a SEER-medicare analysis. Ann Surg Oncol 20:4145-4152

37. Kommission Mamma der Arbeitsgemeinshaft Gynäkologische Onkologie (2015). Diagnosis and treatment of patients with primary and metastatic breast cancer. Deutschen Gesellschaft für Gynäkologie und Geburtshilfe. 2015. http://www.ago.online.de. Accessed Sept 152016
38. Ahmed M, Douek M (2013) Life beyond Z11. Breast 22:1226-1227

39. Farrell TP, Adams NC, Stenson M et al (2015) The Z0011 Trial: Is this the end of axillary ultrasound in the pre-operative assessment of breast cancer patients? Eur Radiol 25:2682-2687

40. Zgajnar J, Hocevar M, Podkrajsek M et al (2006) Patients with preoperatively ultrasonically uninvolved axillary lymph nodes: a distinct subgroup of early breast cancer patients. Breast Cancer Res Treat 97:293-299 